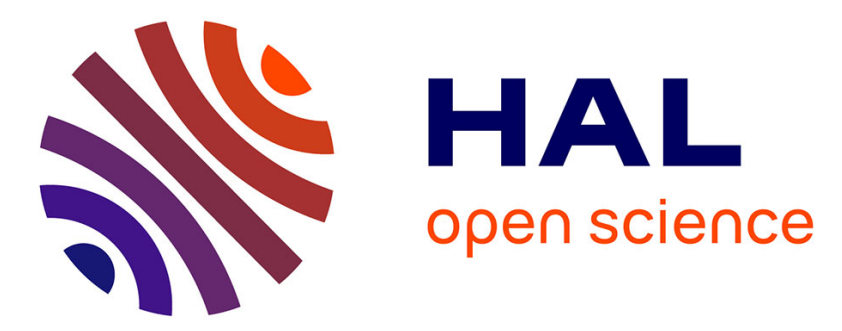

\title{
Septic shock among patients with systemic lupus erythematosus: Short and long-term outcome. Analysis of a French nationwide database
}

\author{
Arthur Mageau, Karim Sacré, Anne Perozziello, Stéphane Ruckly, Claire \\ Dupuis, Lila Bouadma, Thomas Papo, Jean-François Timsit
}

\section{To cite this version:}

Arthur Mageau, Karim Sacré, Anne Perozziello, Stéphane Ruckly, Claire Dupuis, et al.. Septic shock among patients with systemic lupus erythematosus: Short and long-term outcome. Analysis of a French nationwide database. Journal of Infection, 2019, 78, pp.432 - 438. 10.1016/j.jinf.2019.04.005 . hal-03484377

\section{HAL Id: hal-03484377 \\ https://hal.science/hal-03484377}

Submitted on 20 Dec 2021

HAL is a multi-disciplinary open access archive for the deposit and dissemination of scientific research documents, whether they are published or not. The documents may come from teaching and research institutions in France or abroad, or from public or private research centers.
L'archive ouverte pluridisciplinaire HAL, est destinée au dépôt et à la diffusion de documents scientifiques de niveau recherche, publiés ou non, émanant des établissements d'enseignement et de recherche français ou étrangers, des laboratoires publics ou privés.

\section{(ㄷ)(1) $\$$}

Distributed under a Creative Commons Attribution - NonCommerciall 4.0 International 


\title{
Septic shock among patients with systemic lupus erythematosus: short and long-term outcome.
}

\author{
Analysis of a French nationwide database
}

Arthur Mageau*, M.D, Karim Sacré2, M.D, Ph.D, Anne Perozziello*, MSc, Stéphane Ruckly $^{*}$, Msc, Claire Dupuis ${ }^{* 1}$, M.D, PhD, Lila Bouadma ${ }^{\star 1}$, MD, PhD, Thomas Papo², $M D$, Jean-François Timsit ${ }^{\star 1}, M D, P h D$

* IAME UMR1137, Université Paris-Diderot, Equipe 5 DeScID.

1-APHP Medical and infectious diseases ICU Bichat hospital, F75018, Paris

2- Université Paris-Diderot, Assistance Publique Hôpitaux de Paris, Département de Médecine Interne, Hôpital Bichat-Claude Bernard, Paris, France.

Corresponding author: Dr Arthur Mageau, IAME UMR 1137, Université Paris-Diderot Equipe 5 DeScID. arthur_mageau@hotmail.fr;Phone : +33666458941

Conflict of interest statements for each authors: Arthur Mageau: none; Karim Sacré: none; Anne Perozziello: none; Stéphane Ruckly: none; Claire Dupuis: none; Lila Bouadma: none; Thomas Papo: none; Jean-François Timsit: none

Funding: Fondation pour la Recherche Médicale, DEA20170638098 


\section{ABSTRACT}

Objectives: We aimed to assess the characteristics, outcomes and costs of septic shock complicating Systemic Lupus Erythematosus (SLE).

Methods: Characteristics of SLE patients experiencing a septic shock in France from 2010 to 2015 were analyzed through the French medico-administrative database. Factors associated with the 1-year post-admission mortality were analyzed, the crude 1-year survival of SLE patients experiencing septic shock was compared to those admitted for another reason, and we compared the 1-year outcome associated with SLE septic shock survival to a matched SLE ICU control population.

Results: Among 28,522 SLE patients, 1,068 experienced septic shock. The 1-year mortality rate was $43.4 \%$. Independently of the severity, an associated Sjögren syndrome was the only specific SLE phenotype associated with mortality (HR 1.392[1.021-1.899]). Within one year, post-septic shock survivors $(n=738)$ were readmitted 6.42[17.3] times with total cost of $€ 14,431[20,444]$. Unmatched analysis showed that the outcome of patients admitted in ICU for septic shock was poorer than that of patients admitted in ICU or hospital for another disease. However, 1-year healthcare use of septic shock survivors was not different from the other ICU survivors when matched on severity.

Conclusions: Septic shock is a frequent and severe complication among SLE patients even if it is not associated with more healthcare use than another episode of same severity. 


\section{MANUSCRIPT}

Systemic lupus erythematosus (SLE) is one of the most frequent, widespread, autoimmune connective tissue diseases. In addition to specific and nonspecific disease complications, SLE patients are prone to infection, as well as septic shock, either because of immunosuppressive treatment or intrinsic dysregulation of the immune system ${ }^{1}$. For patients with inflammatory systemic disorders, infectious diseases are the first reason for ICU admission ${ }^{2}$.

In France, from 2000 to 2009, among patients with SLE whose death was due to another disease, $10.2 \%$ died from infection ${ }^{3}$. A meta-analysis showed that the standardized mortality risk due to infection in SLE is nearly five times greater than in the general population ${ }^{4}$. Furthermore, recent studies showed that SLE-associated mortality has not improved over the past decades ${ }^{5}$.

Survivors experience a worsening of chronic health conditions, with increased healthcare use and up to $30 \%$ mortality in the year following septic episode ${ }^{6}$. However, very few is known about the burden of septic shock complicating SLE, including specific characteristics, risk factors and prognosis. We wanted to clarify if SLE specific characteristics have an impact on septic shock outcomes and how much healthcare use is modified after a septic shock episode in SLE population. Therefore, we conducted an analysis of a French nationwide database to assess the number, main characteristics, outcome, prognosis and the associated costs of septic shock complicating SLE. 


\section{MATERIALS AND METHODS}

\section{Study population and data source}

Exhaustive data for all patients admitted in French hospitals with at least one SLE diagnosis from January 2009 to December 2015 were collected from the national medical administrative database, the PMSI (Programme de Médicalisation des Systèmes d'Informations, Information System Medicalization Program). PMSI database provides a summary with diagnosis and individual medical conditions at discharge of any public or private French healthcare facilities. Information covers both medical and administrative data. Each facility produces its own anonymous standardized set of data, which are then compiled at the national level. Despite the fact that these data are anonymous, the system allows to follow all hospital stays for each individual patient. Routinely collected medical data include main diagnosis, secondary diagnoses, and performed procedures. Administrative data include age, gender, year, duration of hospital stay, and location of the hospital. In-hospital death is also reported. Diagnoses identified during the hospital stay are coded according to the International Classification of Diseases, tenth revision (ICD-10). Procedures performed during the hospital stay are coded according to the "Classification Commune des Actes Médicaux" (CCAM, French Common Classification of Medical Procedures). Since 2004, each hospital's budget depends on the medical activity described in this specific program. Regular checks are made by the social insurance authority to ensure that data are correctly imputed. In Intensive Care Units (ICU), severity at admission is measured by the Simplified Acute and Physiology Score II 
(SAPS II) and all procedures are recorded. The reliability and validity of PMSI data have been assessed elsewhere ${ }^{78}$.

To select the SLE population, we first extracted from the PMSI database all records of patients for whom at least one ICD-10 M32 diagnosis was reported. We excluded patients younger than 15 years old and patients admitted to hospital only for scheduled sessions (chronic hemodialysis, radiotherapy, chemotherapy). We also excluded the hospital stays identified with an error code $(n=12,190 ; 6 \%)$.

\section{Definitions}

We defined septic shock as the combination of at least one diagnosis of infection (ICD-10 code A00-B99 + others listed in supplementary data) with one diagnosis among the followings: R57.2 "septic shock", R57.8 "other shock", R 57.9 "shock without precision" or CCAM procedure code EQLF0010 and EQLF0030 which refers to the use of vasopressor agents. We considered only the first septic shock, and stays containing or following a M32 diagnosis code to ensure the SLE diagnosis. End-stage renal disease (ESRD) was defined as having received a renal transplant or having required chronic hemodialysis. For the exhaustive description of diagnosis and procedures codes used, see electronic supplementary materials. To determine SLE phenotype, we used all the specific diagnostic codes reported during or before the stay of interest.

Analysis 1: Characteristics, outcome and costs of septic shock in the overall

\section{SLE population}

We described the demographic characteristics, diagnosis and procedures associated with septic shock. For the determinant of the 30-day and 1-year post-ICU admission mortality, we used univariate and multivariate Cox proportional hazard models. The 
first day in ICU defined Time 0. For stays without ICU admission we considered the first day in hospital. For multivariate Cox models, we used gender, chronic kidney disease (CKD) and all variables that had a significance level $<0.20$ as covariates. Hazard ratios are presented as HR [C195]. One-year healthcare use and hospital costs were assessed for survivors for at least 30 days after sepsis.

Analysis 2: Crude comparisons of the 1-year survival in case of septic shock vs. patients with ICU stay without any septic shock.

In a second analysis, we performed a crude comparison of the 1-year survival rate of SLE patients experiencing septic shock versus SLE patients without any septic shock in ICU and versus SLE patients not admitted in ICU. We used Kaplan-Meier method to represent their 1 -year survival taking time 0 as first hospital admission. We then used univariable Cox proportional hazard model to estimate hazard ratio of 1-year death among these populations.

Analysis 3: Comparison of the survival rate and associated costs between SLE septic shock survivors and matched SLE non-septic shock survivors

We performed a 1:1 exposed/non-exposed propensity score matched study where we selected the exposed patients where the SLE patients with a septic shock from January 2010 to December 2014 and discharged alive from ICU. Eligible controls were defined as all the SLE patients without any septic shock and discharged alive from ICU. To build the propensity score we used a logistic regression model with several covariables including gender, Charlson-age adjusted comorbidity index, type of medical facility (university, general public, or private), use of invasive mechanical ventilation and the magnitude of the Simplified Acute Physiology Score II (SAPS II). We used a greedy algorithm to perform the matching. Further details of the matching procedure are available within the electronic supplementary materials. 
On this matched population, we compared several outcomes during the year following time 0 (defined here as the day of hospital discharge): survival with KaplanMeier method, healthcare use (number, duration and cost of following hospitalizations), number of stays in a rehabilitation center, and diagnosis of an endstage renal disease (ESRD).

\section{Statistical analysis}

The median value of the SAPSII was imputed to the $57(0.5 \%)$ missing data. Categorical variables are presented as number (percentage). Quantitative variables are presented as mean [standard deviation]. In the matched analysis we performed a conditional logistic regression procedure adjusted on the propensity score and on the presence of lupus nephritis to test for significance. All tests were two-sided, and $\mathrm{P}$ values $<.05$ were considered to indicate a significant association.

All analyses were performed using SAS @ software version 9.4 (SAS Inc, Cary NC). Kaplan-Meier curves were made with R software version 3.4.4, library "survival".

\section{Ethical statement}

In accordance with French legislation on non-interventional studies with anonymous data, signed informed consent of the participants was not needed (Law n²012-300).

\section{RESULTS}

Analysis 1: Characteristics, outcome and costs of septic shock in the overall SLE population (Table 1 \& Table 2) 
We extracted 1,068 patients experiencing a first episode of septic shock among the whole population of 25,228 SLE patients over 6 years. Sex ratio was (F/M) $75.8 / 24.2 \%$ and $25.6 \%(n=273)$ of these patients had chronic kidney disease (CKD). Most of these stays took place in university hospitals (56.8\%), followed by general hospitals $(39.3 \%)$, whereas only $3.9 \%$ were in private for-profit hospitals (Table 1). The most common associated SLE phenotype was lupus nephritis $(26.3 \%, n=281)$. The lower respiratory tract was the main site of infection $(n=498 ; 46.6 \%)$ and a high proportion of patients had bacteremia $(n=317 ; 29.7 \%)$. Gram-negative bacilli were the most frequent pathogens identified $(n=465 ; 43.5 \%)$. Of note, 102 patients $(9.6 \%)$ had infections due to vaccine-preventable pathogens (e.g., Influenza virus, Streptococcus pneumoniae, Neisseria meninigitidis or Haemophilus influenza). Patients were seriously ill with a mean [SD] SAPS II score of 47 [21.6]. Overall, 913 (85.6\%) patients required vasopressive drugs (epinephrine, norepinephrine), 369 (34.6\%) invasive mechanical ventilation and 342 patients (32.0\%), renal replacement therapy for Acute Kidney Injury (AKI). Patients spent 11.6 [15.6] days in the ICU and 32.8 [32.1] in the hospital, and the mean associated cost was $€ 25,327[23,396]$. The 30 day and 1-year post admission mortality rates were $30.9 \%(n=330)$ and $43.4 \%$ ( $n=463)$, respectively. In- and out-of-hospital outcomes are presented on Table 2.

Determinants of the 1-year mortality are listed in Table 1. Patients' illness severity was the main determinant of mortality. In the univariate analysis, the various SLE phenotypes such as lupus nephritis (HR 0.922 [0.748-1.136]) or serositis (HR 0.973 [0.782-1.211]) were not significantly associated with the prognosis at 1 year. An associated Sjögren syndrome was at the limit of significance for an adverse effect: HR 1.328 [0.976-1.806]. 
In the multivariate analysis, at 1-year after ICU admission, independently of the acute illness severity and comorbidities, an associated Sjögren syndrome (HR: 1,392 $[1,021-1,899])$ was significantly associated with death. Interestingly, the only infectious characteristic associated with increased mortality was fungal infection. In contrast, urinary tract infection was associated with survival (HR 0.701[0.553-0.889]), confirming findings observed in general ICU population with septic shock ${ }^{9}$.

The analysis of the 30-day post-septic shock mortality are presented in ESM and yielded similar results.

Within one year, post-septic shock survivors $(n=738)$ were re-admitted 6.42[17.3] times for 64.1 [48.9] days with a total cost of $€ 14,431$ [20,444], and $12(1.6 \%)$ patients required the initiation of chronic hemodialysis (Table 2).

Analysis 2: Crude comparisons of the 1-year survival in case of septic shock vs. patients with ICU stay without any septic shock

We identified 20,315 SLE patients without ICU admission and 3,845 SLE patients with ICU stay without any septic shock that we compared to the 1,068 SLE patients admitted in ICU and experiencing septic shock. At one year, taking people who were not admitted in the ICU and didn't experience a septic shock as reference, SLE patients had a hazard ratio [CI 95] of 1-year death of 51 [37-61] and 269 [198-365] if they were experiencing a stay in ICU without septic shock or a septic shock, respectively. The 1-year survival was significantly poorer among ICU SLE patients with septic shock $(p<0.0001$, Figure 1$)$. 
Analysis 3: Comparison of the survival rate and associated costs between SLE septic shock survivors and matched SLE non-septic shock survivors

Based on the initial illness severity, we were able to match 404 SLE ICU survivors with septic shock with 404 SLE ICU survivors without any septic shock (Table 3). SLE patients experiencing septic shock had a longer stay in ICU, and in hospital after the ICU, than matched controls. However, as shown in Figure 2, there was no difference in the 1-year mortality between these groups (stratified Log-Rank test, $p$ $=0.46)$. In the septic shock group, 57 patients people died within 1 year vs. 53 in the matched control group. We found no significant difference in 1-year hospital costs (€ $18,346[23,250]$ in case of septic shock vs. $€ 18,460[23,362]$ for controls, $p=0.3276)$, as well as their rate of healthcare use (Table 4). More patients in the control group required the initiation of chronic hemodialysis $(n=39 ; 9.7 \%)$ than in the septic shock group $(n=11(2.7 \%), p<0.001)$.

\section{DISCUSSION}

In a large nationwide exhaustive cohort of SLE patients, we observed that septic shock was associated with a worsened morbidity and mortality. After taking into account the severity of the acute illness and comorbidities, an associated Sjögren syndrome was a factor of poor prognosis. For survivors, the onset of a septic shock appears as a turning point with heavily increased mortality, hospital costs, and healthcare use. However, the outcome of SLE septic shock survivors was not different from that of matched SLE ICU survivors of other diseases. 
In our population of SLE patients, septic shock had a poor prognosis among SLE patients: mortality rates and associated costs were higher than in general population at short term 10111213 and long-term ${ }^{14}$. Indeed, SLE patients, mostly when treated with steroids or immunosuppressive drugs, can be considered as immunocompromised, clearly a determinant of poor prognosis in case of septic shock ${ }^{15}$. The ICU mortality rate of SLE patients with septic shock in France was higher than that previously observed probably because of selection bias in retrospective

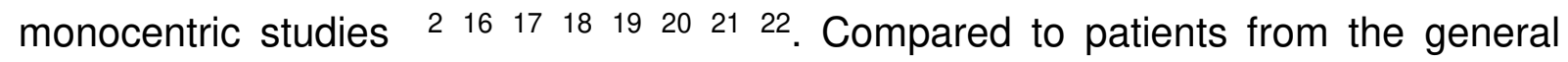
population experiencing septic shock, our SLE patients were younger and more often female. Infection characteristics were similar, except for fungal infections which seemed more frequent among SLE patients ${ }^{11}$.

The observed 1-year costs were higher than previously reported in hospitalized patients with SLE ${ }^{23}$. In comparison to the article of Prescott et al. ${ }^{24}$ who evaluated the 1-year healthcare use in survivors of severe sepsis in a cohort extracted from general population, we observed more healthcare resources used within one year after septic episode in SLE patients. Several reasons could explain this difference: we selected patients only with septic shock, whereas Prescott et al. selected also patients with severe sepsis. In addition, all of our patients had SLE, which can be considered as a severe co-morbidity ${ }^{5}$.

In the matched comparison, SLE patients with septic shock had a prolonged hospital stay and increased in-hospital costs. But the post-ICU mortality and costs were not different between SLE ICU survivors with septic shock vs. those without septic shock. This finding is in contradiction with the study from Prescott et al. who observed a significant increase in the 1-year healthcare use between severe sepsis survivors and matched controls in a general population. The difference might be due to the 
impact of the underlying SLE disease on the 1-year healthcare consumption. Indeed, the rate of patients requiring chronic hemodialysis was higher in the SLE survivors without septic shock. It may also be related to the absence of adjustment on illness severity on ICU admission in the study of Prescott ${ }^{24}$.

Interestingly, we observed that, independently of the severity of the acute illness, associated Sjögren syndrome was a main determinant of the 1-year mortality. In contrast, other reported SLE features and, for example, associated antiphospholipid syndrome were not associated with a poorer 1-year survival. In a large SLE cohort, Sjögren syndrome had already been described as deleterious on damage scores and mortality ${ }^{25}$. To the best of our knowledge, the outcome of in-ICU Sjögren patients had never been evaluated. Sjogren's syndrome is associated with a specific risk of interstitial and cystic lung disease, which could affect both incidence and severity of lower respiratory tract infection ${ }^{26}$. We can postulate that Sjogren's syndrome can adversely affect ICU procedures, especially the invasive mechanical ventilation. Furthermore, infection was reported as the second cause of death among Sjögren patients, meaning that these patients were probably seriously affected by infectious diseases $^{27}$

This study has some limitations. Because it is a hospital database, we had no access to the out-of-the-hospital mortality, healthcare resource use and costs. However, among SLE patients overall, Thomas G. et al showed that in France between 2000 and 2009 , the mortality was mostly $(67.9 \%)$ in-hospital ${ }^{3}$. Though, the only possibility for a patient to get lost to follow up is that he died outside of a hospital or he moved abroad. Another limitation is that PMSI is based on coding diagnosis and procedures and this system might not be always sufficiently accurate. For example, the prevalence of CKD is higher than the one of lupus nephritis, even if it is a population 
of mostly young women without any other reason to develop a CKD. This can be explained by the fact that lupus nephritis may be encoded only for the hospital stay dealing with its management whereas CKD is encoded for all the hospital stay as comorbidity. Therefore, non- or under-measured cofounding factors, especially under-estimated SLE phenotypes (both number and types) could have biased our results. Besides, we can postulate that the coding process is overestimating the prevalence of septic shock in administrative database ${ }^{28}$. Nevertheless, regarding the severity and the outcome of our selected population, we considered that the septic shock definition was reliable.

We believe that this work has also several strengths. First, because of the French Health Insurance System, PMSI gather exhaustive data of all French hospitals, meaning that our data include every patient with at least one diagnosis of SLE hospitalized in France for six years. Severity scores at ICU admission using a wellrecognized general ICU severity score and organ dysfunction daily scores were also exhaustively recorded. The selected population had SLE characteristics (i.e., prevalence, sex ratio, age) consistent with previously published large SLE epidemiologic studies in France ${ }^{29}$. Thanks to the chaining between the successive hospitalization episodes, we were able to examine all records of one individual patient and to assess the 30-day and 1-year outcome. Our matched study enabled us to perform comparisons of SLE patients with matched illness severity and matched levels of comorbidities.

\section{CONCLUSIONS}

Septic shock is a major concern for SLE patients with heavy associated short- and long-term morbidity and mortality. In order to improve SLE prognosis, significant efforts should be made to prevent infectious diseases in this immunocompromised 
population. Vaccination is clearly an issue since we observed in our cohort almost $10 \%$ of septic shock associated with vaccine-preventable pathogens.

ACKNOWLEDGEMENTS: Fondation pour la Recherche Médicale DEA20170638098 (funding). The authors thank Celine Feger,MD (EMIBiotech) for her editorial support. $A M$ is the guarantor of the content of the manuscript, including the data and analysis. $\mathrm{KS}, \mathrm{SR}, \mathrm{AP}, \mathrm{CD}, \mathrm{TP}, \mathrm{LB}$, and JFT contributed substantially to the study design, data analysis and interpretation, and the writing of the manuscript

Figures legends:

Figure 1: One-year survival of SLE patients experiencing septic shock in ICU vs. SLE patients admitted in ICU without septic shock and vs. SLE patients admitted for standard hospitalization (time 0 = first admission). Kaplan-Meier estimator at day 365 is presented with $\mathrm{Cl} 95$ for each group

Figure 2: One-year survival of SLE ICU patients survivors after a septic shocks vs. matched control SLE ICU survivors without any septic shock

Tables: 
Table 1: Characteristics and factors associated with the 1-year mortality of septic shocks among SLE overall population admitted in ICU

\begin{tabular}{|c|c|c|c|c|c|}
\hline & $n=1068$ & Univariate HR & $\mathbf{p}$ & Multivariate HR & $\mathbf{p}$ \\
\hline Age ** & $55.9(+/-16.4)$ & $1.023(1.017-1.030)$ & $<0.0001$ & - & - \\
\hline $\operatorname{Sex}(F / M)$ & $810 / 258(75.8 / 24.2 \%)$ & $0.962(0.7880-1.188)$ & 0.7211 & $1.116(0.900-1.385)$ & 0.3173 \\
\hline \multicolumn{6}{|l|}{ Associated condition } \\
\hline $\begin{array}{c}\text { Chronic kidney disease (eGFR }< \\
60 \mathrm{~mL} / \mathrm{min})\end{array}$ & $273(25.6 \%)$ & $1.181(0.966-1.444)$ & 0.1044 & $1.041(0.848-1.278)$ & 0.704 \\
\hline Cancer** & $112(10.5 \%)$ & $1.660(1.279-2.155)$ & 0.0001 & - & - \\
\hline Diabetes mellitus** & $128(12.0 \%)$ & $0.933(0.704-1.217)$ & 0.631 & - & - \\
\hline Cardiovascular history ** & $454(42.5 \%)$ & $1.221(1.017-1.465)$ & 0.0323 & - & - \\
\hline Charlson - age adjusted comorbidity index & $4.0(+/-1.8)$ & $1.122(1.164-1.283)$ & $<0.001$ & $1.166(1.106-1.228)$ & $<0.0001$ \\
\hline \multicolumn{6}{|l|}{ Associated SLE disease } \\
\hline Lupus nephritis & $281(26.3 \%)$ & $0.922(0.748-1.136)$ & 0.4466 & - & - \\
\hline Serositis & $241(22.6 \%)$ & $0.973(0.782-1.211)$ & 0.8064 & - & - \\
\hline Antiphospholipid syndrom & $103(9.6 \%)$ & $0.793(0.569-1.105)$ & 0.1708 & $0.816(0.584-1.142)$ & 0.235 \\
\hline Sjögren syndrom & $87(8.2 \%)$ & $1.328(0.976-1.806)$ & 0.0708 & $1.392(1.021-1.899)$ & 0.0365 \\
\hline $\begin{array}{c}\text { Number of previous stay with SLE } \\
\text { diagnosis } \\
\text { Characteristics of the shock }\end{array}$ & $4.5(+/-7.9)$ & $1.005(0.995-1.015)$ & 0.3207 & - & - \\
\hline SAPS $\|^{*}$ & $47.0(+/-21.6)$ & $1.024(1.020-1.029)$ & $<0.0001$ & $1.022(1.017-1.026)$ & $<0.0001$ \\
\hline \multicolumn{6}{|l|}{ Infection site : } \\
\hline Bacteriemia & $317(29.7 \%)$ & $1.205(0.992-1.463)$ & 0.06 & $1.071(0.871-1.318)$ & 0.516 \\
\hline Endocarditis & $57(5.3 \%)$ & $1.235(0.853-1.787)$ & 0.2643 & - & - \\
\hline Lower Respiratory tract & $498(46.6 \%)$ & $0.899(0.749-1.080)$ & 0.2551 & $0.881(0.726-1.070)$ & 0.2 \\
\hline Urinary/genital tract & $257(24.1 \%)$ & $0.753(0.599-0.946)$ & 0.0149 & $0.701(0.553-0.889)$ & 0.0034 \\
\hline Abdomen & $224(21.0 \%)$ & $1.186(0.955-1.472)$ & 0.1218 & $1.116(0.895-1.393)$ & 0.3297 \\
\hline CNS* & $51(4.8 \%)$ & $1.110(0.736-1.674)$ & 0.6179 & - & - \\
\hline Bones and joints & $37(3.5 \%)$ & $1.281(0.818-2.005)$ & 0.2788 & - & - \\
\hline Skin & $54(5.1 \%)$ & $0.878(0.567-1.360)$ & 0.5604 & - & - \\
\hline \multicolumn{6}{|l|}{ Pathogens : } \\
\hline Gram positive cocci & $345(32.3 \%)$ & $0.982(0.809-1.192)$ & 0.8511 & - & - \\
\hline Staphylococcus aureus & $140(9.7 \%)$ & $1.078(0.804-1.446)$ & 0.6145 & - & - \\
\hline Streptococcus pneumoniae & $61(5.7 \%)$ & $0.470(0.246-0.799)$ & 0.0054 & - & - \\
\hline Gram negative bacilli & $465(43.5 \%)$ & $0.847(0.704-1.020)$ & 0.0798 & - & - \\
\hline Fungi & $146(13.7 \%)$ & $1.309(1.026-1.670)$ & 0.0301 & $1.371(1.056-1.781)$ & 0.0179 \\
\hline Influenza virus & $24(2.3 \%)$ & $0.598(0.283-1.261)$ & 0.2124 & - & - \\
\hline Viruses & $145(13.6 \%)$ & $0.961(0.736-1.256)$ & 0.771 & - & - \\
\hline Parasites & $23(2.2 \%)$ & $1.405(0.809-2.440)$ & 0.2267 & - & - \\
\hline Pneumocystis jirovecii & $12(1.1 \%)$ & $1.452(0.688-3.064)$ & 0.3275 & - & - \\
\hline Documented Infection & $703(65.8 \%)$ & $0.940(0.776-1.138)$ & 0.5243 & $0.926(0.752-1.141)$ & 0.4723 \\
\hline
\end{tabular}

* SAPS II : Simplified Acute Physiology Score ; CNS Central Nervous System

** Age. cancer. diabetes and cardiovascular history are considered to be part of Charlson-age adjusted index and germ variables to be part of documented infection so these variables were not used in multivariate analysis

Categorical variables are presented as $n$ (\%). quantitative variables are presented as mean (+/-sd) 
Table2: Healthcare use and outcome of SLE patients experiencing septic shock

Septic shock stay $(n=1068)$ :

Duration of the stay in hospital (days)

ICU admission

$32.8(+/-32.1)$

$1,011(94.7 \%)$

Duration of the stay in ICU (days) ( $n=1$ 011)

Cost of the hospital stay (€)

$11.6(+/-15.6)$

Use of pressor amines

Mechanical ventilation

Renal replacement therapy for AKI

Short and long-term outcome ( $n=1068)$ :

Death at 30 days post admission

Death at 1 year post admission

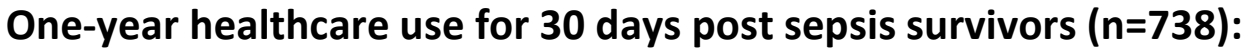

Number of hospitalizations

$25,327(+/-23396)$

$913(85.6 \%)$

$369(34.6 \%)$

$342(32.0 \%)$

$330(30.9 \%)$

$463(43.4 \%)$

$6.42(+/-17.3)$

Total cost (€)

$14,431(+/-20444)$

Categorical variables are presented as $n(\%)$, quantitative variables are presented as mean(+/-sd) 
Table 3: Baseline characteristics of SLE septic shock survivors and matched SLE ICU survivors

Septic shocks $(\mathrm{n}=404)$

$$
\begin{gathered}
\text { Age } \\
\text { Sex }(F / M)^{*}
\end{gathered}
$$

\section{Associated condition}

Chronic kydney disease (eGFR $<60 \mathrm{~mL} / \mathrm{min}$ )

End-stage renal disease

Cancer

Diabetes mellitus

Cardiovascular history

Charlson - age adjusted comorbidity index *

\section{Characteristics of the stay}

Kind of medical facility (University/General/Private)*

Time interval between ICU admission and ICU discharge (days)

Time interval between ICU discharge and hospital discharge (days)

Time intervalbetween ICU admission and hospital discharge (days)

Cost of the hospital stay (€)

\section{Associated SLE phenotypes}

Lupus nephritis

Serositis

Antiphospholipid syndrom

sjögren syndrom

\section{Characteristics of the shock}

\section{SAPS II *}

Use of pressor amines

Invasive mechanical ventilation *

Renal replacement therapy for AKI
$52.0(+/-16.2)$

$313 / 91(77.5 / 22.5 \%)$

$107(26.5 \%)$

$50(12.4 \%)$

$28(6.9 \%)$

$51(12.6 \%)$

$153(37.9 \%)$

$3.6(+/-1.7)$

236/156/12 (58.4/38.6/3.0\%)

$11.1(+/-13.5)$

$16,1(+/-21,7)$

$27.2(+/-23.0)$

$27794(+/-24218)$

$61(15.1 \%)$

24 (5.9\%)

24 (5.9\%)

$13(3.2 \%)$

$39.4(+/-14.8)$

371 (91.8\%)

$103(25.5 \%)$

$101(25.0 \%)$
Controls $(n=404)$

$51.1(+/-16.3)$

$317 / 87$ (78.5/21.5\%)

147 (36.4\%)

$63(15.6 \%)$

28 (6.9\%)

36 (8.9\%)

141 (34.9\%)

$3.5(+/-1.6)$

259/134/11

(64.1/33.2/2.7\%)

$7.0(+/-8.1)$

$11,4(+/-14,7)$

$18.4(+/-15.8)$

$17819(+/-13$ 396)

$83(20.5 \%)$

$19(4.7 \%)$

19 (4.7\%)

10 (2.5\%)

39.3(+/-13.8)

$66(16.3 \%)$

98 (24.3\%)

99 (24.5\%)

Categorical variables are presented as $n(\%)$, quantitative variables are presented as mean (+/-sd). *variables used to build the propensity score 
Table 4: One-year outcome, healthcare use and costs of SLE septic shock ICU survivors and matched SLE ICU survivors without any septic shock

Septic shocks ( $\quad$ Controls $(n=404) \quad p^{*}$ =404)

$57(14.1 \%) \quad 53(12.9 \%) \quad 0.6015$

Number of hospitalisations :

Total

Standard hospitalizations

Sessions**

ICU

Days spen $t$ in a hospital facility :

Total healthcare-associated cost for one patient :

With initial stay's cost

Without initial stay's cost

Number of stays in a rehabilation center

Apparition of ESRD
$11.2(+/-26.4)$

$2.9(+/-6.7)$

$6.8(+/-26.0)$

$1.6(+/-1.0)$

$45.8(+/-67.5)$

$46141(+/-34764)$

$18346(+/-23250)$

$0.33(+/-0.7)$

11 (2.7\%)
$15.2(+/-32.1)$

0.1915

$3.3(+/-5.4)$

0.296

$10.5(+/-30.8)$

0.2268

$1.5(+/-0.8)$

0.2168

$54.2(+/-86.2)$

0.3897

$36274(+/-27120)$

$<0.0001$

$18460(+/-23362)$

0.3276

0.3080

0.0003

${ }^{*} p$ value is adjusted on the initial presence of lupus nephritis and on the propensity score

** "Sessions" means a planned visit that last less than a day

Categorical variables are presented as $n(\%)$, quantitative variables are presented as mean (+/-sd). 


\section{REFERENCES}

1 Ruiz-Irastorza Guillermo, Olivares Nerea, Ruiz-Arruza loana, Martinez-Berriotxoa Agustin, Egurbide Maria-Victoria, Aguirre Ciriaco. Predictors of major infections in systemic lupus erythematosus. Arthritis Res Ther 2009;11(4):R109. Doi: 10.1186/ar2764.

2 Dumas Guillaume, Géri Guillaume, Montlahuc Claire, Chemam Sarah, Dangers Laurence, Pichereau Claire, et al. Outcomes in Critically III Patients With Systemic Rheumatic Disease: A Multicenter Study. CHEST 2015;148(4):927-35. Doi: 10.1378/chest.14-3098.

3 Thomas Guillemette, Mancini Julien, Jourde-Chiche Noémie, Sarlon Gabrielle, Amoura Zahir, Harlé Jean-Robert, et al. Mortality associated with systemic lupus erythematosus in France assessed by multiple-cause-of-death analysis. Arthritis Rheumatol Hoboken NJ 2014;66(9):2503-11. Doi: 10.1002/art.38731.

4 Yurkovich Marko, Vostretsova Kateryna, Chen Wenjia, Aviña-Zubieta J Antonio. Overall and CauseSpecific Mortality in Patients With Systemic Lupus Erythematosus: A Meta-Analysis of Observational Studies. Arthritis Care Res 2014;66(4):608-16. Doi: 10.1002/acr.22173.

5 Jorge April M, Lu Na, Zhang Yuqing, Rai Sharan K, Choi Hyon K. Unchanging premature mortality trends in systemic lupus erythematosus: a general population-based study (1999-2014). Rheumatology n.d. Doi: 10.1093/rheumatology/kex412.

6 Prescott Hallie C, Angus Derek C. Enhancing Recovery From Sepsis: A Review. JAMA 2018;319(1):62-75. Doi: 10.1001/jama.2017.17687.

7 Couris Chantal Marie, Polazzi Stephanie, Olive Frederic, Remontet Laurent, Bossard Nadine, Gomez Frederic, et al. Breast cancer incidence using administrative data: correction with sensitivity and specificity. J Clin Epidemiol 2009;62(6):660-6. Doi: 10.1016/j.jclinepi.2008.07.013.

8 Chantry Anne A, Deneux-Tharaux Catherine, Cans Christine, Ego Anne, Quantin Catherine, Bouvier-Colle Marie-Hélène, et al. Hospital discharge data can be used for monitoring procedures and intensive care related to severe maternal morbidity. J Clin Epidemiol 2011;64(9):1014-22. Doi: 10.1016/j.jclinepi.2010.11.015.

9 Zahar Jean-Ralph, Timsit Jean-Francois, Garrouste-Orgeas Maïté, Français Adrien, Vesin Aurélien, Vesim Aurélien, et al. Outcomes in severe sepsis and patients with septic shock: pathogen species and infection sites are not associated with mortality. Crit Care Med 2011;39(8):1886-95. Doi: 10.1097/CCM.0b013e31821b827c.

10 Kaukonen Kirsi-Maija, Bailey Michael, Suzuki Satoshi, Pilcher David, Bellomo Rinaldo. Mortality Related to Severe Sepsis and Septic Shock Among Critically III Patients in Australia and New Zealand, 2000-2012. JAMA 2014;311(13):1308-16. Doi: 10.1001/jama.2014.2637.

11 Quenot Jean-Pierre, Binquet Christine, Kara Fady, Martinet Olivier, Ganster Frederique, Navellou Jean-Christophe, et al. The epidemiology of septic shock in French intensive care units: the prospective multicenter cohort EPISS study. Crit Care Lond Eng/ 2013;17(2):R65. Doi: $10.1186 /$ cc12598. 
12 Stoller Jeremy, Halpin Laura, Weis Matthew, Aplin Brett, Qu Weikai, Georgescu Claudiu, et al. Epidemiology of severe sepsis: 2008-2012. J Crit Care 2016;31(1):58-62. Doi:

10.1016/j.jcrc.2015.09.034.

13 Adrie Christophe, Alberti Corinne, Chaix-Couturier Carine, Azoulay Élie, Lassence Arnaud de, Cohen Yves, et al. Epidemiology and economic evaluation of severe sepsis in France: age, severity, infection site, and place of acquisition (community, hospital, or intensive care unit) as determinants of workload and cost. J Crit Care 2005;20(1):46-58. Doi: 10.1016/j.jcrc.2004.10.005.

14 Brinkman Sylvia, de Jonge Evert, Abu-Hanna Ameen, Arbous M Sesmu, de Lange Dylan W, de Keizer Nicolette F. Mortality after hospital discharge in ICU patients. Crit Care Med 2013;41(5):1229-36. Doi: 10.1097/CCM.0b013e31827ca4e1.

15 Jamme Matthieu, Daviaud Fabrice, Charpentier Julien, Marin Nathalie, Thy Michaël, Hourmant Yannick, et al. Time Course of Septic Shock in Immunocompromised and Nonimmunocompromised Patients. Crit Care Med 2017;45(12):2031-9. Doi: 10.1097/CCM.0000000000002722.

16 Siripaitoon B, Lertwises S, Uea-Areewongsa P, Khwannimit B. A study of Thai patients with systemic lupus erythematosus in the medical intensive care unit: epidemiology and predictors of mortality. Lupus 2015;24(1):98-106. Doi: 10.1177/0961203314548884.

17 Han BK, Bhatia R, Traisak P, Hunter K, Milcarek B, Schorr C, et al. Clinical presentations and outcomes of systemic lupus erythematosus patients with infection admitted to the intensive care unit. Lupus 2013;22(7):690-6. Doi: 10.1177/0961203313490240.

18 Hsu Chia-Lin, Chen Kuan-Yu, Yeh Pu-Sheng, Hsu Yeong-Long, Chang Hou-Tai, Shau Wen-Yi, et al. Outcome and prognostic factors in critically ill patients with systemic lupus erythematosus: a retrospective study. Crit Care 2005;9(3):R177-83. Doi: 10.1186/cc3481.

19 Whitelaw DA, Gopal R, Freeman V. Survival of patients with SLE admitted to an intensive care unita retrospective study. Clin Rheumatol 2005;24(3):223-7. Doi: 10.1007/s10067-004-1007-3.

20 Feng Po-Hao, Lin Shu-Min, Yu Chih-Teng, Yu Kuang-Hui, Huang Chien-Da, Tsai Ying-Huang, et al. Inadequate antimicrobial treatment for nosocomial infection is a mortality risk factor for systemic lupus erythematous patients admitted to intensive care unit. Am J Med Sci 2010;340(1):64-8. Doi: 10.1097/MAJ.0b013e3181e0ef9b.

21 Alzeer AH, Arfaj A Al-, Basha SJ, Alballa S, Wakeel J Al-, Arfaj H Al-, et al. Outcome of patients with systemic lupus erythematosus in intensive care unit. Lupus 2004;13(7):537-42. Doi: 10.1191/0961203304lu1057oa.

22 Ansell SM, Bedhesi S, Ruff B, Mahomed AG, Richards G, Mer M, et al. Study of critically ill patients with systemic lupus erythematosus. Crit Care Med 1996;24(6):981-4.

23 Li Tracy, Carls Ginger Smith, Panopalis Pantelis, Wang Sara, Gibson Teresa B, Goetzel Ron Z. Longterm medical costs and resource utilization in systemic lupus erythematosus and lupus nephritis: a five-year analysis of a large medicaid population. Arthritis Rheum 2009;61(6):755-63. Doi: 10.1002/art.24545.

24 Prescott Hallie C, Langa Kenneth M, Liu Vincent, Escobar Gabriel J, Iwashyna Theodore J. Increased 1-year healthcare use in survivors of severe sepsis. Am J Respir Crit Care Med 2014;190(1):62-9. 
Doi: $10.1164 / \mathrm{rccm} .201403-04710 C$.

25 Chambers SA, Charman SC, Rahman A, Isenberg DA. Development of additional autoimmune diseases in a multiethnic cohort of patients with systemic lupus erythematosus with reference to damage and mortality. Ann Rheum Dis 2007;66(9):1173-7. Doi: 10.1136/ard.2006.062984.

26 Lechtman Sarah, Debray Marie-Pierre, Crestani Bruno, Bancal Catherine, Hourseau Muriel, Dossier Antoine, et al. Cystic lung disease in Sjögren's syndrome: An observational study. Jt Bone Spine Rev Rhum 2017;84(3):317-21. Doi: 10.1016/j.jbspin.2016.05.019.

27 Brito-Zerón P, Kostov B, Solans R, Fraile G, Suárez-Cuervo C, Casanovas A, et al. Systemic activity and mortality in primary Sjögren syndrome: predicting survival using the EULAR-SS Disease Activity Index (ESSDAI) in 1045 patients. Ann Rheum Dis 2016;75(2):348-55. Doi: 10.1136/annrheumdis-2014-206418.

28 Rhee Chanu, Murphy Michael V, Li Lingling, Platt Richard, Klompas Michael, Centers for Disease Control and Prevention Epicenters Program. Comparison of trends in sepsis incidence and coding using administrative claims versus objective clinical data. Clin Infect Dis Off Publ Infect Dis Soc Am 2015;60(1):88-95. Doi: 10.1093/cid/ciu750.

29 Arnaud Laurent, Fagot Jean-Paul, Mathian Alexis, Paita Michel, Fagot-Campagna Anne, Amoura Zahir. Prevalence and incidence of systemic lupus erythematosus in France: a 2010 nation-wide population-based study. Autoimmun Rev 2014;13(11):1082-9. Doi: 10.1016/j.autrev.2014.08.034. 


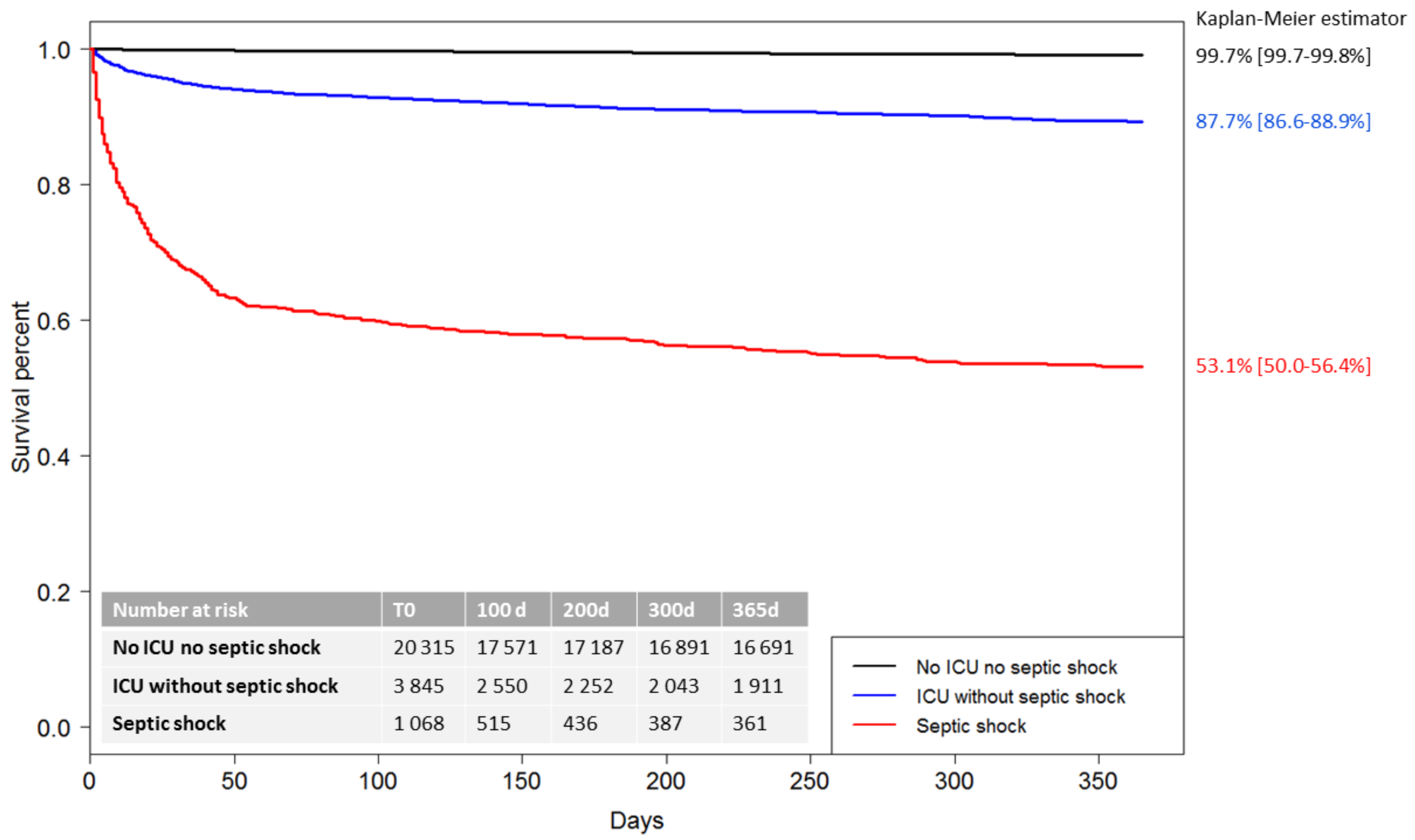




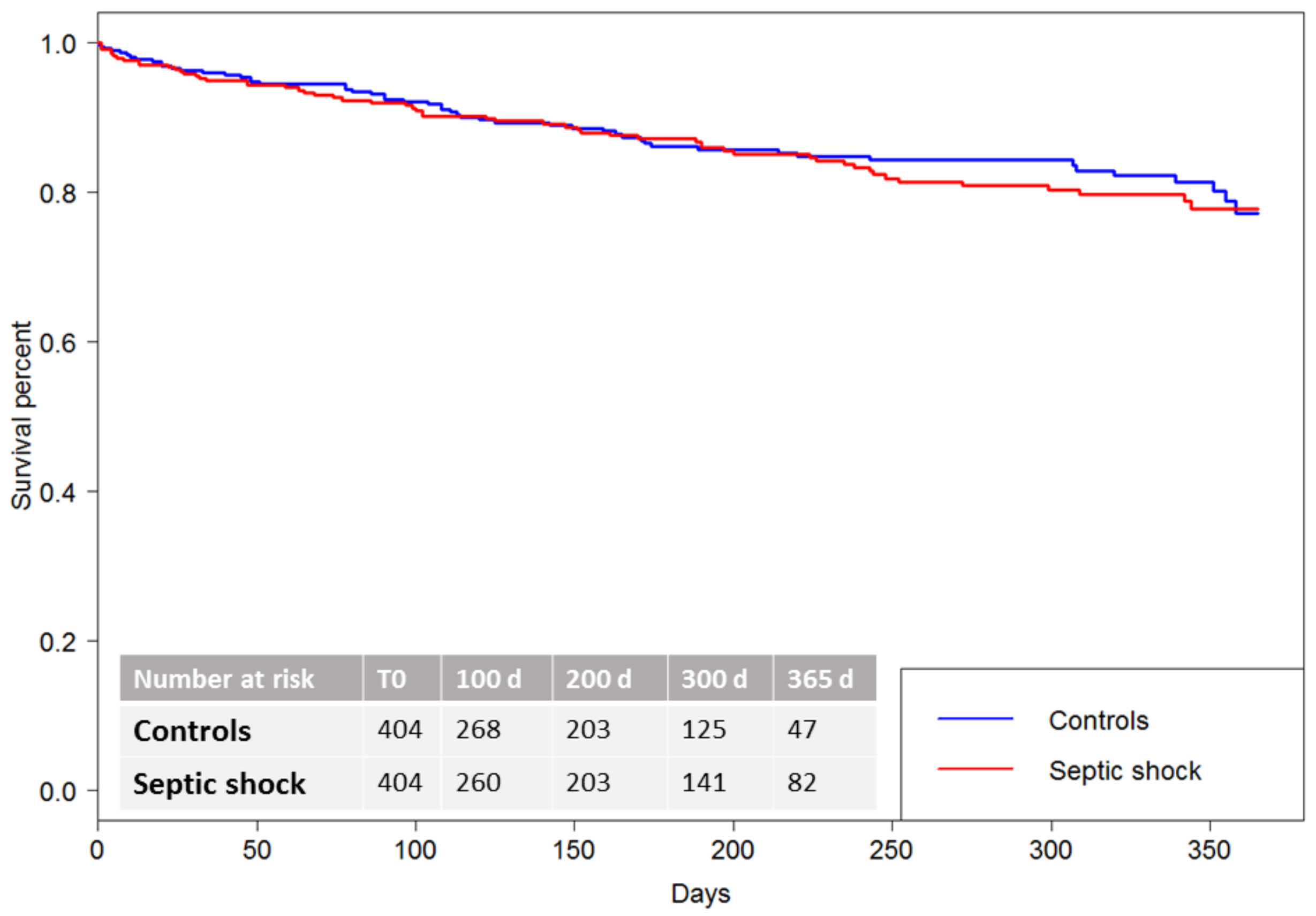


Table 1: Characteristics and factors associated with the 1-year mortality of septic shocks among SLE overall population admitted in ICU

\begin{tabular}{|c|c|c|c|c|c|}
\hline & $n=1068$ & Univariate HR & $\mathbf{p}$ & Multivariate HR & $\mathbf{p}$ \\
\hline Age ** & $55.9(+/-16.4)$ & $1.023(1.017-1.030)$ & $<0.0001$ & - & - \\
\hline $\operatorname{Sex}(F / M)$ & $810 / 258(75.8 / 24.2 \%)$ & $0.962(0.7880-1.188)$ & 0.7211 & $1.116(0.900-1.385)$ & 0.3173 \\
\hline \multicolumn{6}{|l|}{ Associated condition } \\
\hline \multicolumn{6}{|l|}{$\begin{array}{l}\text { kidney disease (eGFR < } \\
60 \mathrm{~mL} / \mathrm{min})\end{array}$} \\
\hline Cancer** & $112(10.5 \%)$ & $1.660(1.279-2.155)$ & 0.0001 & - & - \\
\hline Diabetes mellitus** & $128(12.0 \%)$ & $0.933(0.704-1.217)$ & 0.631 & - & - \\
\hline Cardiovascular history $* *$ & $454(42.5 \%)$ & $1.221(1.017-1.465)$ & 0.0323 & - & - \\
\hline Charlson - age adjusted comorbidity index & $4.0(+/-1.8)$ & $1.122(1.164-1.283)$ & $<0.001$ & $1.166(1.106-1.228)$ & $<0.0001$ \\
\hline \multicolumn{6}{|l|}{ Associated SLE disease } \\
\hline Lupus nephritis & $281(26.3 \%)$ & $0.922(0.748-1.136)$ & 0.4466 & - & - \\
\hline Serositis & $241(22.6 \%)$ & $0.973(0.782-1.211)$ & 0.8064 & - & - \\
\hline Antiphospholipid syndrom & $103(9.6 \%)$ & $0.793(0.569-1.105)$ & 0.1708 & $0.816(0.584-1.142)$ & 0.235 \\
\hline Sjögren syndrom & $87(8.2 \%)$ & $1.328(0.976-1.806)$ & 0.0708 & $1.392(1.021-1.899)$ & 0.0365 \\
\hline $\begin{array}{c}\text { Number of previous stay with SLE } \\
\text { diagnosis } \\
\text { Characteristics of the shock }\end{array}$ & $4.5(+/-7.9)$ & $1.005(0.995-1.015)$ & 0.3207 & - & - \\
\hline SAPS $I^{*}$ & $47.0(+/-21.6)$ & $1.024(1.020-1.029)$ & $<0.0001$ & $1.022(1.017-1.026)$ & $<0.0001$ \\
\hline \multicolumn{6}{|l|}{ Infection site : } \\
\hline Bacteriemia & $317(29.7 \%)$ & $1.205(0.992-1.463)$ & 0.06 & $1.071(0.871-1.318)$ & 0.516 \\
\hline Endocarditis & $57(5.3 \%)$ & $1.235(0.853-1.787)$ & 0.2643 & - & - \\
\hline Lower Respiratory tract & $498(46.6 \%)$ & $0.899(0.749-1.080)$ & 0.2551 & $0.881(0.726-1.070)$ & 0.2 \\
\hline Urinary/genital tract & $257(24.1 \%)$ & $0.753(0.599-0.946)$ & 0.0149 & $0.701(0.553-0.889)$ & 0.0034 \\
\hline Abdomen & $224(21.0 \%)$ & $1.186(0.955-1.472)$ & 0.1218 & $1.116(0.895-1.393)$ & 0.3297 \\
\hline CNS* & $51(4.8 \%)$ & $1.110(0.736-1.674)$ & 0.6179 & - & - \\
\hline Bones and joints & $37(3.5 \%)$ & $1.281(0.818-2.005)$ & 0.2788 & - & - \\
\hline Skin & $54(5.1 \%)$ & $0.878(0.567-1.360)$ & 0.5604 & - & - \\
\hline \multicolumn{6}{|l|}{ Pathogens : } \\
\hline Gram positive cocci & $345(32.3 \%)$ & $0.982(0.809-1.192)$ & 0.8511 & - & - \\
\hline Staphylococcus aureus & $140(9.7 \%)$ & $1.078(0.804-1.446)$ & 0.6145 & - & - \\
\hline Streptococcus pneumoniae & $61(5.7 \%)$ & $0.470(0.246-0.799)$ & 0.0054 & - & - \\
\hline Gram negative bacilli & $465(43.5 \%)$ & $0.847(0.704-1.020)$ & 0.0798 & - & - \\
\hline Fungi & $146(13.7 \%)$ & 1.309 (1.026-1.670) & 0.0301 & $1.371(1.056-1.781)$ & 0.0179 \\
\hline Influenza virus & $24(2.3 \%)$ & $0.598(0.283-1.261)$ & 0.2124 & - & - \\
\hline Viruses & $145(13.6 \%)$ & $0.961(0.736-1.256)$ & 0.771 & - & - \\
\hline Parasites & $23(2.2 \%)$ & $1.405(0.809-2.440)$ & 0.2267 & - & - \\
\hline Pneumocystis jirovecii & $12(1.1 \%)$ & $1.452(0.688-3.064)$ & 0.3275 & - & - \\
\hline Documented Infection & $703(65.8 \%)$ & $0.940(0.776-1.138)$ & 0.5243 & $0.926(0.752-1.141)$ & 0.4723 \\
\hline
\end{tabular}

* SAPS II : Simplified Acute Physiology Score ; CNS Central Nervous System

** Age. cancer. diabetes and cardiovascular history are considered to be part of Charlson-age adjusted index and germ variables to be part of documented infection so these variables were not used in multivariate analysis 
Table2: Healthcare use and outcome of SLE patients experiencing septic shock

Septic shock stay $(n=1068)$ :

Duration of the stay in hospital (days)

$32.8(+/-32.1)$

ICU admission

$1,011(94.7 \%)$

$11.6(+/-15.6)$

Duration of the stay in ICU (days) ( $n=1$ 011)

Cost of the hospital stay $(€)$

$25,327(+/-23396)$

Use of pressor amines

$913(85.6 \%)$

Mechanical ventilation

Renal replacement therapy for AKI

369 (34.6\%)

$342(32.0 \%)$

Short and long-term outcome ( $n=1068)$ :

Death at 30 days post admission

330 (30.9\%)

Death at 1 year post admission

$463(43.4 \%)$

One-year healthcare use for $\mathbf{3 0}$ days post sepsis survivors $(\mathbf{n = 7 3 8 ) :}$

Number of hospitalizations

$6.42(+/-17.3)$

Total cost (€)

$14,431(+/-20444)$

Categorical variables are presented as $n(\%)$, quantitative variables are presented as mean(+/-sd) 
Table 3: Baseline characteristics of SLE septic shock survivors and matched SLE ICU survivors

Age
$\operatorname{Sex}(F / M)^{*}$

Associated condition

Chronic kydney disease (eGFR $<60 \mathrm{~mL} / \mathrm{min}$ )

End-stage renal disease

Cancer

Diabetes mellitus

Cardiovascular history

Charlson - age adjusted comorbidity index *

$52.0(+/-16.2)$

$313 / 91(77.5 / 22.5 \%)$

$107(26.5 \%)$

$50(12.4 \%)$

$28(6.9 \%)$

$51(12.6 \%)$

$153(37.9 \%)$

$3.6(+/-1.7)$

\section{Characteristics of the stay}

Kind of medical facility (University/General/Private)*

Time interval between ICU admission and ICU discharge (days)

Time interval between ICU discharge and hospital discharge (days)

Time intervalbetween ICU admission and hospital discharge (days)

Cost of the hospital stay $(€)$
$236 / 156 / 12(58.4 / 38.6 / 3.0 \%)$

$11.1(+/-13.5)$

$16,1(+/-21,7)$

$27.2(+/-23.0)$

$27794(+/-24218)$

$61(15.1 \%)$

$24(5.9 \%)$

$24(5.9 \%)$

$13(3.2 \%)$

$39.4(+/-14.8)$

$371(91.8 \%)$

103 (25.5\%)

$101(25.0 \%)$
Controls $(n=404)$

$51.1(+/-16.3)$

$317 / 87$ (78.5/21.5\%)

147 (36.4\%)

63 (15.6\%)

28 (6.9\%)

36 (8.9\%)

141 (34.9\%)

$3.5(+/-1.6)$

259/134/11

(64.1/33.2/2.7\%)

$7.0(+/-8.1)$

$11,4(+/-14,7)$

$18.4(+/-15.8)$

17819 (+/- 13 396)

$83(20.5 \%)$

19 (4.7\%)

19 (4.7\%)

$10(2.5 \%)$

39.3(+/-13.8)

$66(16.3 \%)$

98 (24.3\%)

99 (24.5\%) 
Table 4: One-year outcome, healthcare use and costs of SLE septic shock ICU survivors and matched SLE ICU survivors without any septic shock

\begin{tabular}{|c|c|c|c|}
\hline & $\begin{array}{c}\text { Septic shocks (n } \\
=404)\end{array}$ & Controls $(n=404)$ & $p^{*}$ \\
\hline Death & $57(14.1 \%)$ & $53(12.9 \%)$ & 0.6015 \\
\hline \multicolumn{4}{|l|}{ Number of hospitalisations : } \\
\hline Total & $11.2(+/-26.4)$ & $15.2(+/-32.1)$ & 0.1915 \\
\hline Standard hospitalizations & $2.9(+/-6.7)$ & $3.3(+/-5.4)$ & 0.296 \\
\hline Sessions & $6.8(+/-26.0)$ & $10.5(+/-30.8)$ & 0.2268 \\
\hline$I C U$ & $1.6(+/-1.0)$ & $1.5(+/-0.8)$ & 0.2168 \\
\hline Days spen $t$ in a hospital facility : & $45.8(+/-67.5)$ & $54.2(+/-86.2)$ & 0.3897 \\
\hline \multicolumn{4}{|c|}{ althcare-associated cost for one patient : } \\
\hline With initial stay's cost & $46141(+/-34764)$ & $36274(+/-27120)$ & $<0.0001$ \\
\hline Without initial stay's cost & $18346(+/-23250)$ & $18460(+/-23362)$ & 0.3276 \\
\hline umber of stays in a rehabilation center & $0.33(+/-0.7)$ & $0.30(+/-0.6)$ & 0.3080 \\
\hline Apparition of ESRD & $11(2.7 \%)$ & $39(9.7 \%)$ & 0.0003 \\
\hline
\end{tabular}

Total healthcare-associated cost for one patient :

With initial stay's cost

Without initial stay's cost

Number of stays in a rehabilation center

$$
\begin{gathered}
11.2(+/-26.4) \\
2.9(+/-6.7) \\
6.8(+/-26.0) \\
1.6(+/-1.0)
\end{gathered}
$$

$46141(+/-34764)$
$54.2(+/-86.2)$

${ }^{*} p$ value is adjusted on the initial presence of lupus nephritis and on the propensity score

** "Sessions" means a planned visit that last less than a day

Categorical variables are presented as $n(\%)$, quantitative variables are presented as mean $(+/-s d)$. 